\title{
Indo-Pacific seagrass beds and mangroves contribute to fish density and diversity on adjacent coral reefs
}

\author{
M. Dorenbosch, M. G. G. Grol, M. J. A. Christianen, I. Nagelkerken*, \\ G. van der Velde
}

Department of Animal Ecology and Ecophysiology, Institute for Water and Wetland Research, Faculty of Science, Radboud University Nijmegen, Toernooiveld 1, 6525 ED, Nijmegen, The Netherlands

\begin{abstract}
There is a long-standing debate whether mangrove and seagrass habitats in the IndoPacific region function as nurseries for coral reef fishes. We studied the use of all major shallow-water habitat types by juvenile coral reef fish using visual census surveys at 4 islands along the Tanzanian coast (East Africa) and at the island of Grande Comoros (Comoros archipelago). We investigated the value of mangroves, seagrass beds, coral reefs, macroalgae and intertidal flats as a juvenile habitat for fish by studying density distribution patterns of juveniles and adults of 76 reef fish species in these habitats. We assessed (1) which part of the reef fish community used mangrove-seagrass habitats as juvenile or adult habitats, (2) whether adult fish densities and diversity on adjacent reefs were related to the presence of these shallow habitats, and (3) whether adults of species that use these habitats when juvenile were less abundant on coral reefs situated far away from these juvenile habitats. Seagrass beds and coral reefs were the most important juvenile fish habitats. Ontogenetic migrations between seagrass beds and reef habitats possibly occur, since several species showed their highest juvenile densities on seagrass beds, whereas adults showed their highest densities on reefs adjacent to these seagrass beds. The presence of areas with seagrass beds positively influenced adult densities of many reef fish species on adjacent coral reefs. Of the 36 fish species whose juveniles were observed in seagrass beds along the Tanzanian coast, 32 species were absent from or showed low densities on coral reefs of the island of Grande Comoros (lacking seagrass beds or mangroves). On reefs far from seagrass beds and mangroves along the Tanzanian coast, 25 of these 36 species were absent or showed low densities in comparison with reefs adjacent to these habitats.
\end{abstract}

KEY WORDS: Coral reef fish - Seagrass beds - Mangroves - Juveniles - Habitat connectivity · Indian Ocean

\section{INTRODUCTION}

Throughout the tropics, shallow-water habitats such as seagrass beds and mangroves are favoured as juvenile habitats by marine fish, and it is assumed that they function as nursery areas (reviewed by Pollard 1984, Parrish 1989, Beck et al. 2001, Sheridan \& Hays 2003). It is thought that these habitats can contribute to fish communities on the coral reef through migration of adults or subadults from these nurseries. Results from various studies in the Caribbean support this hypo- thesis and show that the presence of seagrass beds or mangroves significantly influences the composition of the fish community on adjacent coral reefs (Nagelkerken et al. 2000a, 2002, Dorenbosch et al. 2004, Halpern 2004, Mumby et al. 2004).

There is a long-standing debate on whether mangroves and seagrass beds in the Indo-Pacific region function as important juvenile habitats for reef fish (Birkeland \& Amesbury 1988, Thollot \& Kulbicki 1988, Williams 1991). Many studies suggested the nursery function of mangroves in the Indo-Pacific region to be 
relatively minor, and have concluded that there is less interaction between mangroves and other coastal habitats than in the Caribbean (Quinn \& Kojis 1987, Robertson \& Duke 1987, Thollot \& Kulbicki 1988, Kimani et al. 1996, Laroche et al. 1997, Huxham et al. 2004). Other studies, however, did report the presence of juvenile coral reef fish in mangrove areas (Lal et al. 1984, Little et al. 1988, Robertson \& Duke 1990, Wakwabi \& Mees 1999, de Boer et al. 2001). Hence, the importance of Indo-Pacific mangroves for juvenile fish remains unclear.

Unlike mangroves, seagrass beds in the Indo-Pacific region are commonly used by juvenile coral reef fish (Jones \& Chade 1975, Kimani et al. 1996, Kochzius 1997, Gullström et al. 2002, Nakamura \& Sano $2004 \mathrm{a}, \mathrm{b})$. This means that seagrass beds may have a greater value as juvenile habitats for reef fish than mangroves. So far, however, there have been no studies in the Indo-Pacific comparing the value of mangroves, seagrass beds and coral reefs as juvenile habitats for reef fish using a uniform methodology.

The weakness of the majority of the studies on the value of mangroves and seagrass beds as juvenile fish habitats is that they have examined only a single habitat or a few habitats simultaneously. This is an important limitation, as in the absence of one shallow habitat, another may take over its function. More importantly, hardly any published study compared fish densities of juveniles and adults in various shallowwater habitats with those on adjacent coral reefs in order to determine whether these shallow-water habitats could contribute to adult fish populations on the reef. Only Blaber \& Blaber (1980) made such comparison between estuaries and adjacent offshore sandy habitats, and Nakamura \& Sano (2004b) between seagrass beds and a coral reef. High densities of juvenile reef fish in mangroves and seagrass beds alone do not prove their importance as nurseries, because (1) these habitats could merely function as sinks of juveniles if adults or subadults do not migrate to adjacent coral reefs (Beck et al. 2001), and (2) other shallow-water habitats may harbour similar or higher densities of juveniles. Various studies have shown that other shallow habitats can also be used as juvenile habitats by reef fish that are normally known to occur in high densities in seagrass beds or mangroves (Jenkins \& Wheatley 1998, Nagelkerken et al. 2000a, Rossier \& Kulbicki 2000, Dorenbosch et al. 2004).

Studying the importance of mangroves and seagrass beds for juvenile fish requires that all available major shallow-water habitats are investigated simultaneously, while densities of fish in the adult habitat (i.e. adjacent coral reef) should also be determined, using a uniform, standardised sampling methodology. Such an approach was used in the present study off the coast of several islands along the East African coast to test the hypothesis that mangroves and seagrass beds function as important habitats for reef fish in the IndoPacific. The main research questions were the following: (1) To what extent do juvenile and adult coral reef fish use shallow-water habitats present in an area, including mangroves, seagrass beds and coral reefs? (2) Are the densities of coral reef fish populations on adjacent reefs related to the presence of mangroveseagrass habitats? (3) Are adult coral reef fish that use mangrove-seagrass habitats in high densities as juveniles less abundant on coral reefs situated far away from these juvenile habitats?

\section{MATERIALS AND METHODS}

Study areas. The present study was carried out off the islands of Mafia, Pemba, Zanzibar and Mbudya along the coast of Tanzania (East Africa) and off the island of Grande Comoros in the Comoros archipelago in the western Indian Ocean (Fig. 1). Nine major shallow-water habitat types were distinguished there (Table 1): mangroves within marine bays (mg); shallow seagrass beds (depth $<5 \mathrm{~m}$ ) situated in marine bays at a distance $<500 \mathrm{~m}$ from mangroves (bay sg); shallow seagrass beds (depth $<5 \mathrm{~m}$ ) outside bays and adjacent to coral reefs (reef sg); deep seagrass beds (depth $>5 \mathrm{~m}$ ) outside bays and adjacent to coral reefs (deep reef sg); an intertidal flat with patches of small coral, rubble, sand and seagrass beds (intertidal flat); sand flats covered by beds of macroalgae (algae flat); coral reefs adjacent to areas with extensive seagrass beds and mangroves (sg-mg reefs); coral reefs situated far away from seagrass beds and mangroves (far reefs); and fringing coral reefs lacking these shallow-water habitats off the island of Grande Comoros (Comoros reefs). The average minimum distance from the far reefs to areas with extensive seagrass beds and mangroves (sg-mg areas) was $17.2 \mathrm{~km}(\mathrm{SD} \pm 5.8)$. Far reefs off the islands of Mbudya, Pemba and Zanzibar were isolated from sg-mg areas and sg-mg reefs by water with a depth $>45 \mathrm{~m}$ (Fig. 1). Far reefs off the island of Mafia were isolated by a large bare sandy seabed with a maximum depth of $25 \mathrm{~m}$.

Off the islands of Mafia, Zanzibar and Pemba, we sampled mangroves, seagrass beds and coral reefs. Although present, seagrass beds and mangroves off the island of Mbudya could not be surveyed because of difficult access in the field. Coral reefs on Grande Comoros were selected because mangroves and seagrass beds were completely lacking, allowing this island to serve as a true control site to study the effect of the absence of mangrove/seagrass habitats on the adult reef fish population. Algae flats and intertidal 


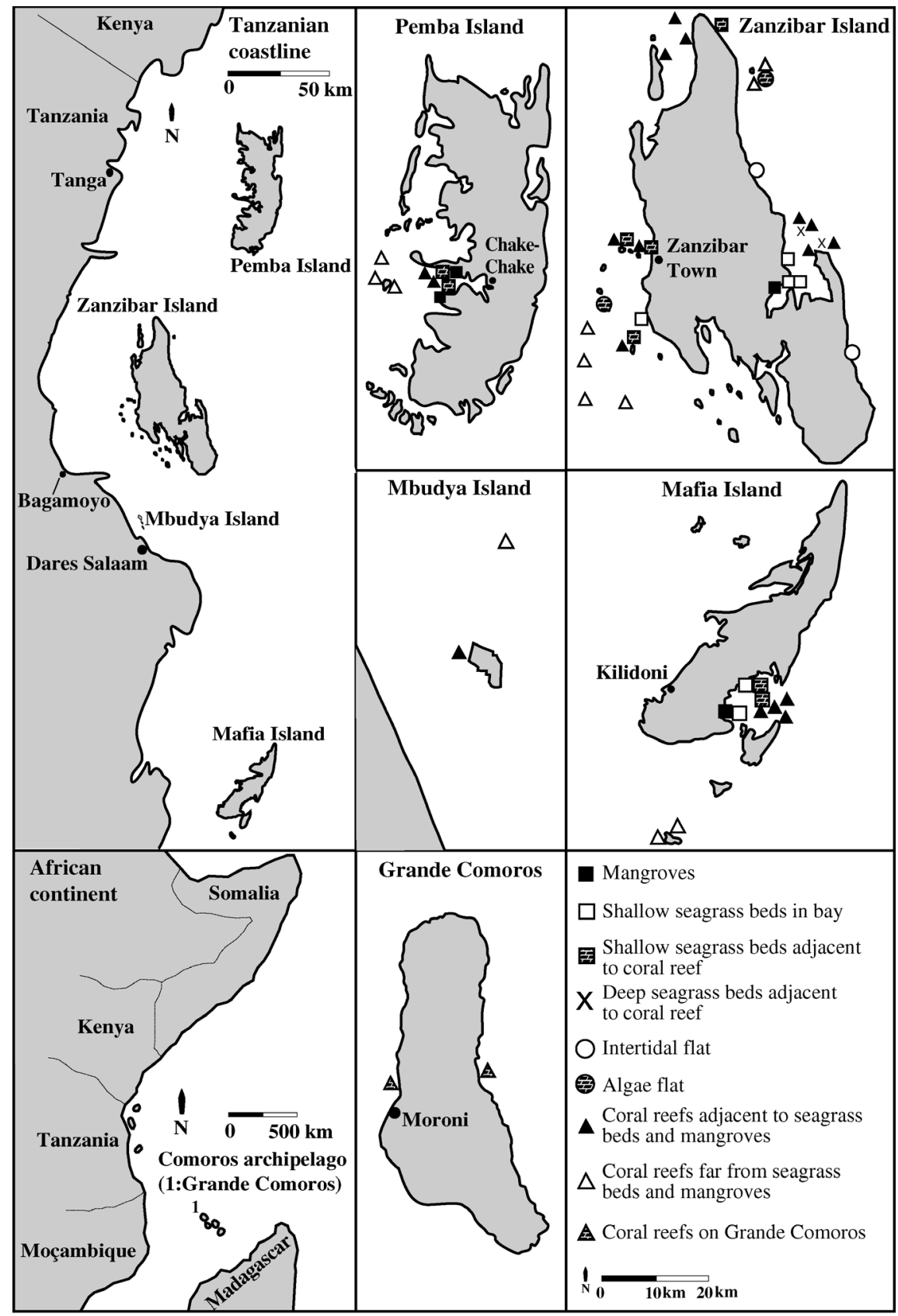

Fig. 1. Overview of the study area (island of Zanzibar, latitude $6^{\circ} 10^{\prime} \mathrm{S}$, longitude $39^{\circ} 10^{\prime} \mathrm{E}$; island of Grande Comoros, latitude $11^{\circ} 40^{\prime} \mathrm{S}$, longitude $43^{\circ} 10^{\prime} \mathrm{E}$ ) and locations of the investigated habitat types

flats were examined only off Zanzibar. All mangroves studied were non-estuarine, normally fell dry during low tide, and were dominated by Sonneratia alba. All surveyed seagrass beds were dominated by Thalassodendron ciliatum ( $>60 \%$ cover), sometimes intermingled with Enhalus acoroides, Thalassia hemprichii or Cymodocea rotundata. Algae flats consisted of a mixture of the macroalgae Turbinaria sp. and Sargassum sp. Sg-mg reefs were predominantly patch reefs surrounded by sand, seagrass beds or macroalgae. Far reefs consisted of fringing and patch reefs surrounding sand banks. Underwater visibility in seagrass beds and mangroves and on coral reefs close to these habitats (sg-mg reefs) was generally poorer (4 to $12 \mathrm{~m}$ ) than visibility on the far reefs or Comoros reefs (10 to $30 \mathrm{~m})$. Spring tidal range is approximately $3.6 \mathrm{~m}$ for Mafia, Mbudya, Pemba and Zanzibar and $3.3 \mathrm{~m}$ for the Grande Comoros (Richmond 2002). 
Table 1. Overview of the total number of sampled quadrats per habitat type per island. Numbers in parentheses show the number of sampled locations per island. Numbers in bold print relate to quadrats with a surface area of $64 \mathrm{~m}^{2}$, other quadrats were $25 \mathrm{~m}^{2}$. Bay sg: shallow seagrass beds (depth $<5 \mathrm{~m}$ ) situated in a bay with mangroves; Reef sg: shallow seagrass beds (depth $<5 \mathrm{~m}$ ) adjacent to coral reef; Deep reef sg: deep seagrass beds (depth $>5 \mathrm{~m}$ ) adjacent to coral reef; Sg-mg reef: coral reefs adjacent to areas containing extensive seagrass beds and mangroves; Far reefs: coral reefs situated far from seagrass beds and mangroves; Comoros reefs: coral reefs on the island of Grande Comoros

\begin{tabular}{|c|c|c|c|c|c|c|}
\hline Habitat & Zanzibar & Pemba & Mafia & Mbudya & $\begin{array}{l}\text { Grande } \\
\text { Comoros }\end{array}$ & $\begin{array}{l}\text { Total sampled } \\
\text { area }\left(\mathrm{m}^{2}\right)\end{array}$ \\
\hline Mangroves & $9(1)$ & $37(2)$ & $36(1)$ & - & - & 2050 \\
\hline Bay sg & $123(4)$ & - & $101(2)$ & - & - & 5600 \\
\hline Reef sg & $121(4)$ & $31(2)$ & $74(2)$ & - & - & 5650 \\
\hline Deep reef sg & $65(2)$ & - & - & - & - & 1625 \\
\hline Intertidal flat & $262(2)$ & - & - & - & - & 6550 \\
\hline Algae flat & $125(2)$ & - & - & - & - & 3125 \\
\hline Sg-mg reefs & 359 (10) & $79(2)$ & $128(4)$ & $44(1)$ & - & 17941 \\
\hline Far reefs & $377(6)$ & $101(3)$ & $68(2)$ & 40 (1) & - & 37504 \\
\hline Comoros reefs & - & - & - & - & $97(2)$ & 6208 \\
\hline
\end{tabular}

Field sampling and study design. Reef fish species were selected based on our ability to identify them in underwater visual censuses, as well as on their commercial value for fisheries (Jiddawi \& Stanley 1997). All species belonging to the families Gerreidae, Haemulidae, Lethrinidae, Lutjanidae, Monodactylidae, Mullidae, Nemipteridae, Plotosidae, Scaridae and Siganidae were included, as well as 2 species of Acanthuridae (Acanthurus leucosternon and Naso unicornis), 2 species of Chaetodontidae (Chaetodon mellanotus and C. auriga), 4 large-sized species of Labridae (Cheilinus fasciatus, C. trilobatus, C. undulatus and Cheilio inermis) and 1 species of Zanclidae (Zanclus cornutus).

Data of the selected reef fish species in all distinguished habitat types were sampled by underwater visual census using SCUBA and a stationary point-count method (Polunin \& Roberts 1993, Watson \& Quinn 1997). Although Rhizophora mangroves have dense, large prop root structures that diminish efficiency of underwater visual census of the habitat, Sonneratia alba is characterized by a large central stem and short stumpy upright pneumatophores. The habitat is therefore very accessible for observers and underwater visual census data can be collected in the same way as in other habitat types due to its relatively open character. Because underwater visibility differed between the various locations, we surveyed $5 \times 5 \mathrm{~m}$ quadrats in areas with a visibility between 5 and $8 \mathrm{~m}$ ( $\mathrm{mg}$, bay sg, reef $\mathrm{sg}$, deep reef $\mathrm{sg}$, intertidal flat, algae flat and sg-mg reefs) and $8 \times 8 \mathrm{~m}$ quadrats in habitats where the visibility was $>8 \mathrm{~m}$ (Comoros reefs and far reefs). Data of each habitat were collected simultaneously by 3 observers who independently surveyed different quadrats.

Depending on quadrat size, a single rope with a length of 5 or $8 \mathrm{~m}$ was used as a visual reference for the quadrat size. After placing the line, the observer waited $3 \mathrm{~min}$ in order to minimize fish disturbance. All target species within or passing through the quadrat were then counted over a period of $10 \mathrm{~min}$. During the first $7 \mathrm{~min}$, the observer waited on the edge of the quadrat, while during the last $3 \mathrm{~min}$, the observer moved through the quadrat to search for small juvenile fish hiding behind corals or other structures. Care was taken not to count individuals or groups of fish that moved in and out of the quadrat more than once. Fish were classified into $2.5 \mathrm{~cm}$ size classes using an underwater slate. Surveys were conducted between 09:00 and 16:00 $\mathrm{h}$ at either high or low tide, when water movement was minimal. Shallow habitats with depths between 0 and $4 \mathrm{~m}$ (mangroves, shallow seagrass beds, algae flat, intertidal flat and shallow parts of coral reefs) could only be surveyed at high tide. Species identification and quantification were first thoroughly practiced simultaneously by the 3 observers until their results were similar. Estimation of size classes was trained by repeatedly estimating the sizes of 50 pieces of electrical wire of known lengths placed at random underwater and representing all fish size classes. Training was continued until the differences in size estimation were minimal (i.e. a deviation of no more than $\pm 2.5 \mathrm{~cm}$ from the actual length for objects $<20 \mathrm{~cm}$ ). Practicing quantification and size estimation was repeated regularly during the visual census period.

Habitats were surveyed during the northeast monsoon in the period September 2003 to February 2004. All habitats at a particular location were sampled until either the total area of a habitat had been surveyed (if the habitat area at the location was small), or a representative part had been surveyed (if the habitat area was very large). 
Coral reefs in the study area were divided into patch reefs and fringing reefs. Patch reefs consisted mainly of 1 coral zone with a relatively constant depth, while fringing coral reefs consisted of a shallow reef flat, a drop-off and a reef slope. Quadrats on coral reefs were surveyed in all coral zones that could be distinguished. Coral cover below a depth of 20 m was generally low. Since pilot surveys had revealed that $>90 \%$ of the individuals of the target species were present between depths of 0 and $20 \mathrm{~m}$, deeper reef habitats were not surveyed. Table 1 lists the total number of sampled quadrats per habitat type per island.

Since fish densities are often correlated with the degree of habitat complexity (Luckhurst \& Luckhurst 1978, Öhman \& Rajasuriya 1998, Garpe \& Öhman 2003), the total coral cover (living and dead stony corals, and living soft corals) and the maximum height of the corals (in decimetres) were visually quantified for each quadrat. To estimate coral cover, a quadrat was divided into 4 quarters, after which coral cover was estimated for each individual quarter and then averaged for the whole quadrat. When diving circumstances were good enough, coral reef rugosity was also measured for each quadrat. A $5 \mathrm{~m}$ rope was attached to the substratum in the quadrat and stretched to obtain a horizontal line. Rugosity of the reef was measured by draping a chain over the corals along the $5 \mathrm{~m}$ line. The chain length (in decimetres) was then used as a measure of reef rugosity. The estimations of coral cover, maximum coral height and reef rugosity in each quadrat were made immediately after the visual census. Because the water depth of the various coral reefs varied and depth may influence the occurrence of reef fish (Green 1996, Ault \& Johnson 1998), the water depth (in metres) of each quadrat was recorded using a diving computer.

Data analysis. Fish were recorded as juveniles when they were smaller than one-third of the maximum species length (Nagelkerken \& van der Velde 2002). Maximum lengths of species were obtained from FishBase World Wide Web (Froese \& Pauly 2003). Specimens of species with a maximum length $>90 \mathrm{~cm}$ were recorded as juveniles when they were $<30 \mathrm{~cm}$. For those species whose maturation size was known, the one-third-of-maximum-length rule was found to be suitable to define juveniles. This was tested for Chaetodon auriga, Diagramma pictum, Chlorurus sordidus, Lethrinus lentjan, L. nebulosus, Lutjanus fulviflamma, L. kasmira, L. lutjanus, Parupeneus macronema and Scarus psittacus.

In all statistical analyses, each individual quadrat was used as a replicate. For each habitat type, mean densities of juveniles and adults were calculated per species (based on all locations per habitat type). Based on these mean densities, species were classified into 7 species groups: seagrass residents (sg residents), nursery species, seagrass generalists (sg generalists), generalists, reef generalists, reef residents and rare species. Criteria used for this classification were arbitrarily chosen and are defined in Table 2. Although the term nursery species is often subject of discussion (Beck et al. 2001), we here used the term to describe species that show high juvenile densities in seagrass beds and high adult densities on reef habitats.

We also calculated the mean total fish density (pooling observed species of all size classes per quadrat) and mean total species richness for each habitat type. Because quadrat sizes varied (25 or $64 \mathrm{~m}^{2}$ ), species richness could not be directly compared between these quadrats. To compare habitat types, quadrat size was standardized by pooling fish counts of five $25 \mathrm{~m}^{2}$ quadrats (total area $125 \mathrm{~m}^{2}$ ) or two $64 \mathrm{~m}^{2}$ quadrats (total area $128 \mathrm{~m}^{2}$ ). Differences in total fish density and species richness between the 6 non-reef habitats (mg, bay $s g$, reef $s g$, deep reef $s g$, intertidal flat and algae flat) and between the 3 reef habitats (sg-mg reefs, far reefs and Comoros reefs) were tested using a nonparametric Kruskal-Wallis test followed by a Dunnet T3 post-hoc comparison test (Sheskin 1997). Fish densities and species richness of standardized quadrats were used as replicates.

The influences of cover, height and rugosity of the corals and of the quadrat depth on adult fish density were tested by means of multiple linear regressions for each species. Juvenile densities were generally too low to allow multiple linear regressions. For each multiple linear regression, adult fish density per quadrat was used as the dependent variable, and mean coral cover, maximum coral height, reef rugosity and quadrat depth as regressors. Possible multicollinearity between the 4 regressors was investigated by 6 additional simple linear regressions between coral cover (regressor) and maximum coral height, coral cover (regressor) and coral rugosity, quadrat depth (regressor) and coral cover, quadrat depth (regressor) and maximum coral height, quadrat depth (regressor) and coral rugosity and between maximum coral height (regressor) and coral rugosity. Linear regressions were significant between coral cover and maximum coral height $(\mathrm{p}<0.001$; $\left.\mathrm{R}^{2}=0.04\right)$, quadrat depth and coral cover $(\mathrm{p}=0.001$; $\mathrm{R}^{2}=0.01$ ) and maximum coral height and coral rugosity $\left(p<0.001 ; R^{2}=0.06\right)$. Since $R^{2}$ values were very low, multicollinearity between these variables is considered insignificant.

The influence of the presence of sg-mg areas on adult fish density on coral reefs (sg-mg reefs, far reefs and Comoros reefs) was tested using a general linear model (GLM). This was done using 2 analyses: one GLM compared adult fish density between sg-mg reefs and far reefs, while a second GLM compared adult fish 
density between sg-mg reefs and Comoros reefs. These 2 GLMs were run for each of the 7 species groups (pooling all adult fish species per quadrat) except 'rare species' (Tables 2 \& 3), and for all fish species separately. To increase normality of the data set, fish data were transformed by $y=\sqrt{(0.5+x)}$. Adult fish density was used as the dependent variable in both GLMs and each individual quadrat was used as a replicate. The presence or absence of sg-mg areas was used as a fixed factor in both models. Because multiple linear regressions showed depth to be a significant factor for $41 \%$ of the species (see 'Results'), quadrat depth was used as a covariable in each GLM. Type III sum of squares was used in both models. For each performed analysis, model assumptions were checked. If the assumptions were violated, the analysis was not performed. GLMs were not performed for the 'rare species' group. All analyses were performed using SPSS version 11.5.

\section{RESULTS}

\section{Species groups and habitat utilisation}

Both total fish density and species richness were significantly higher on reef sg than in all other non-reef habitats (Fig. 2, Table 3). This was also true for bay sg, except that no significant difference in species richness was found with intertidal flat and algae flat. A comparison of the habitat types in the mangroveseagrass bed-coral reef gradient (see Fig. 1) shows a clear spatial trend (Fig. 2). Both total fish density and species richness increase from mangroves to reef sg habitats and decline from sg-mg reefs to Comoros reefs. In this spatial gradient, the bay and reef habitat types located most closely to each other (i.e. reef sg and sg-mg reefs) showed the highest total fish densities and species rich-
Table 2. Criteria used to classify fish species into 7 species groups; sg-mg: all seagrass (both shallow and deep) and mangrove habitats, excluding intertidal flats and algae flats; reef: both sg-mg reefs and far reefs, excluding Comoros reefs. PJD: mean partial juvenile density; TJD: mean total juvenile density; PAD: mean partial adult density; TAD: mean total adult density. In partial density, mean fish density (juveniles or adults) of sg-mg habitats or reef habitats is expressed as percentage of mean total fish density (juveniles or adults). See Table 1 for habitat abbreviations

\begin{tabular}{|c|c|c|}
\hline Species group & Occurrence of juveniles & Occurrence of adults \\
\hline Seagrass residents & PJD sg-mg $>70 \%$ of TJD & PAD sg-mg $>70 \%$ of TAD \\
\hline Nursery species & PJD sg-mg $>70 \%$ of TJD & $\mathrm{PAD}$ reef $>70 \%$ of $\mathrm{TAD}$ \\
\hline Seagrass generalists & PJD sg-mg $>70 \%$ of TJD & $\begin{array}{l}\text { Both PAD sg-mg and PAD } \\
\text { reef between } 30-70 \% \text { of } \\
\text { TAD }\end{array}$ \\
\hline Generalists & $\begin{array}{l}\text { Both PJD sg-mg and PJD } \\
\text { reef between } 30-70 \% \text { of } \\
\text { TJD }\end{array}$ & $\begin{array}{l}\text { Both PAD sg-mg and PAD } \\
\text { reef between } 30-70 \% \text { of } \\
\text { TAD }\end{array}$ \\
\hline Reef generalists & $\begin{array}{l}\text { Both PJD sg-mg and PJD } \\
\text { reef between } 30-70 \% \text { of } \\
\text { TJD }\end{array}$ & $\mathrm{PAD}$ reef $>70 \%$ of $\mathrm{TAD}$ \\
\hline Reef residents & PJD reef $>70 \%$ of TJD & $\mathrm{PAD}$ reef $>70 \%$ of $\mathrm{TAD}$ \\
\hline Rare species & \multicolumn{2}{|c|}{$\begin{array}{l}\text { Mean total fish density (pooling juveniles and adults } \\
\text { per quadrat) }<0.20 \text { individuals } 100 \mathrm{~m}^{-2} \text { (based on all } \\
\text { habitats together) }\end{array}$} \\
\hline
\end{tabular}

Table 3. Results of statistical comparison (expressed as p-values) of mean total fish density (A) and mean total species richness (B) between the 6 non-reef habitats and the 3 reef habitats (Kruskal-Wallis test followed by a Dunnet T3 post-hoc comparison, see also Fig. 2). NS: not significant

\begin{tabular}{|c|c|c|c|c|c|c|}
\hline \multicolumn{7}{|c|}{$\begin{array}{l}\text { Non-reef habitats: } \\
\text { Kruskal-Wallis test: } \mathrm{p}<0.001 \\
\text { Dunnet T3 post-hoc comparisons: }\end{array}$} \\
\hline Mangroves & $\begin{array}{l}\mathrm{A} \\
\mathrm{B}\end{array}$ & $\begin{array}{l}<0.001 \\
<0.001\end{array}$ & $\begin{array}{l}<0.001 \\
<0.001\end{array}$ & $\begin{array}{c}\text { NS } \\
0.006\end{array}$ & $\begin{array}{c}\text { NS } \\
<0.001\end{array}$ & $\begin{array}{l}\text { NS } \\
0.017\end{array}$ \\
\hline Bay seagrass & $\begin{array}{l}\text { A } \\
\text { B }\end{array}$ & & $\begin{array}{l}0.020 \\
0.009\end{array}$ & $\begin{array}{r}<0.001 \\
0.023\end{array}$ & $\begin{array}{c}<0.001 \\
\mathrm{NS}\end{array}$ & $\begin{array}{c}<0.001 \\
\text { NS }\end{array}$ \\
\hline Reef seagrass & $\begin{array}{l}\text { A } \\
\text { B }\end{array}$ & & & $\begin{array}{l}<0.001 \\
<0.001\end{array}$ & $\begin{array}{l}<0.001 \\
<0.001\end{array}$ & $\begin{array}{l}<0.001 \\
<0.001\end{array}$ \\
\hline $\begin{array}{c}\text { Deep reef } \\
\text { seagrass }\end{array}$ & $\begin{array}{l}\text { A } \\
\text { B }\end{array}$ & & & & $\begin{array}{l}\text { NS } \\
\text { NS }\end{array}$ & $\begin{array}{l}\text { NS } \\
\text { NS }\end{array}$ \\
\hline Intertidal flat & $\begin{array}{l}\text { A } \\
\text { B }\end{array}$ & & & & & $\begin{array}{l}\text { NS } \\
\text { NS }\end{array}$ \\
\hline \multicolumn{7}{|c|}{$\begin{array}{l}\text { Reef habitats: } \\
\text { Kruskal-Wallis test: } \mathrm{p}<0.001 \\
\text { Dunnet T3 post-hoc comparisons: }\end{array}$} \\
\hline $\begin{array}{l}\text { Sg-mg reefs } \\
\text { Far reefs }\end{array}$ & $\begin{array}{l}\text { A } \\
\text { B } \\
\text { A } \\
\text { B }\end{array}$ & $\begin{array}{l}0.010 \\
0.049\end{array}$ & $\begin{array}{l}<0.001 \\
<0.001 \\
<0.001 \\
<0.001\end{array}$ & & & \\
\hline
\end{tabular}



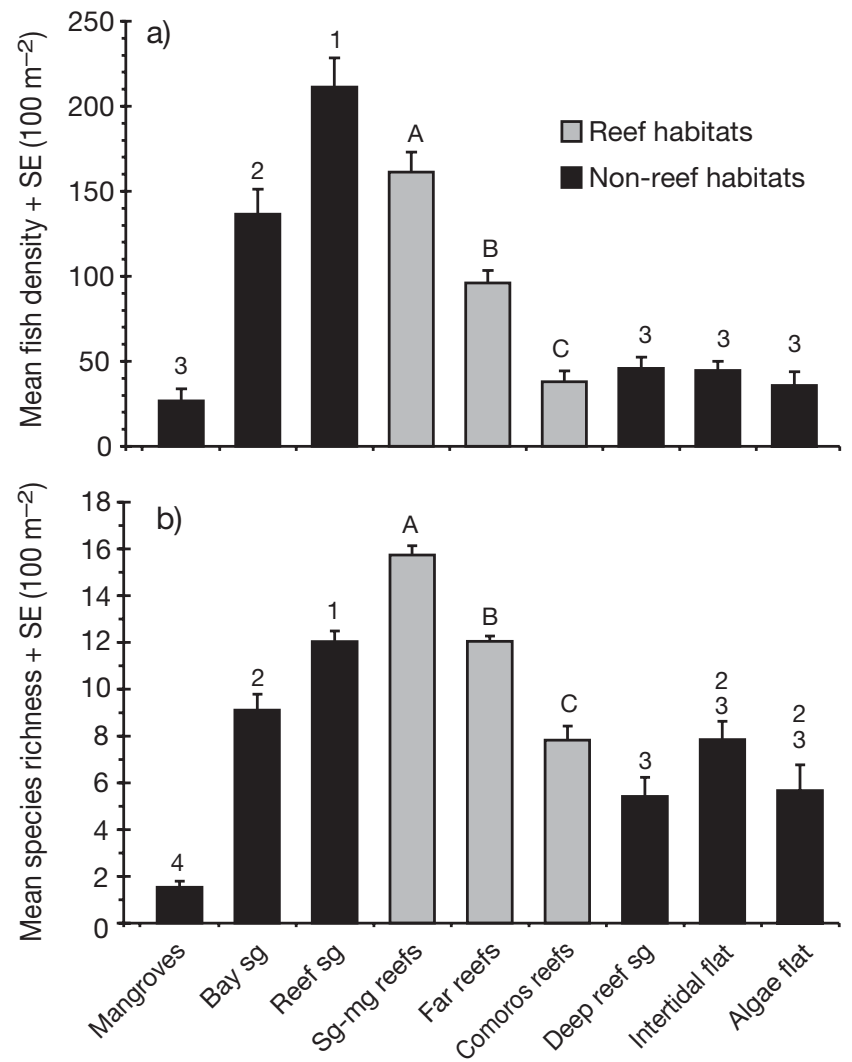

Fig. 2. (a) Mean total fish density and (b) mean total species richness in all investigated habitat types, based on standardized quadrat sizes (see text). Mangroves, bay sg, reef sg, sgmg reefs, far reefs and Comoros reefs are arranged according to a distance gradient. Mean total fish densities and mean species richness are compared for non-reef habitats and for reef habitats using a Kruskal-Wallis test and Dunnet T3 post-hoc comparisons (see also Table 4). Different numbers indicate significant differences between non-reef habitats; different letters indicate significant differences between reef habitats. See Table 1 for habitat abbreviations

ness, whereas the bay and reef habitats located furthest away from this transition (i.e. mg and Comoros reefs) showed lowest total fish densities and species richness.

In total, 76 species of the selected fish families were observed in the quadrats in the study area, and these were classified into the 7 distinguished species groups (Table 4). The number of species per species group that were observed on islands where both reef and non-reef habitats were sampled (Zanzibar, Mafia and Pemba) did not differ much between these islands. Reef residents were represented by the largest number of species ( $\mathrm{n}=32,42 \%$ of all observed species,) while the other groups were represented by considerably smaller numbers of species (ranging from 4 to 11 species). For 36 species (48\% of all observed species) that were observed in the reef quadrats either as juveniles or adults, more than $30 \%$ of the total juvenile density (see criteria in Table 2) was observed in sg-mg habitats (i.e. all species of seagrass residents, nursery species, seagrass generalists, generalists and reef generalists, see Table 4). According to the criteria listed in Table 2, 18 of these species ( $24 \%$ of all species) had their highest juvenile densities in sg-mg habitats (i.e. species of sg residents, nursery species and sg generalists), while the other 18 species showed similar juvenile densities in sg-mg habitats and reef habitats (i.e. species of generalists and reef generalists).

Differences in juvenile densities between seagrass and other habitats were largest for sg residents, nursery species and sg generalists. These species groups all had their highest juvenile densities in seagrass beds, and were only observed in low densities in reef habitats (Fig. 3a). Reef residents, on the other hand, had much higher juvenile densities in reef habitats than in non-reef habitats. Although generalists and reef generalists also had high juvenile densities in shallow sg habitats, differences with juvenile densities in other shallow-habitat types and in reefs habitats were considerably smaller. Sg generalists were the only species group with relatively high densities of juveniles in mangroves. Juvenile densities on Comoros reefs were only high for the reef residents.

As regards adults, only sg residents showed much higher densities in sg-mg habitats than in reef habitats (Fig. 3b). The nursery species, reef generalists and reef residents, on the other hand, had much higher adult densities in reef habitats than in sg-mg habitats. Just as for juveniles, adult densities on Comoros reefs were only high for the reef residents. For all other species groups, adult densities on Comoros reefs were low or zero.

\section{Effect of the presence of sg-mg habitats on reef fish densities}

Multiple linear regressions between adult fish density and the 3 coral complexity variables and quadrat depth showed a significant relation for coral cover (20 species), maximum coral height (16 species), coral rugosity (5 species) and quadrat depth (31 species). All species groups except rare species contained species for which multiple regressions were significant. However, in all cases where a significant relationship was observed, both the part correlations (correlation of the dependent variable with one of the regressors, where the effect of the other regressors on the dependent variable is controlled) of the individual variables and the $\mathrm{R}^{2}$ value of the complete model were very low (most part correlations were $<0.15$, while the highest observed part correlation was 0.21 , and almost all $\mathrm{R}^{2}$ values for the complete model were $<0.1$ ). 


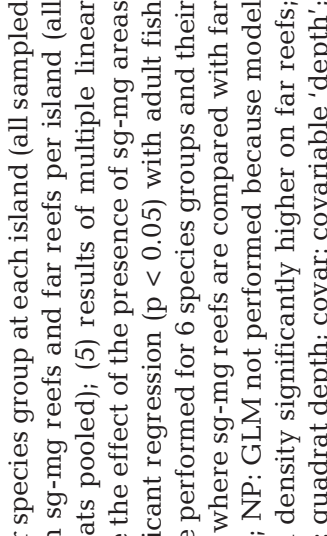

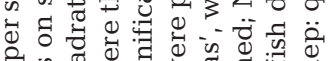

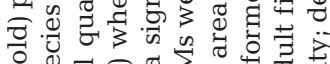

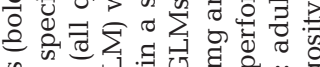

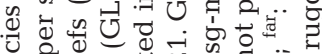
on 0

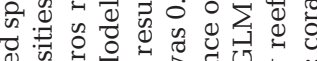

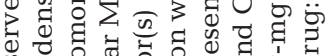
记

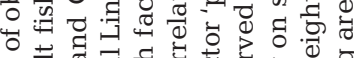

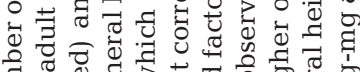
의

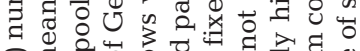
สิ तुक

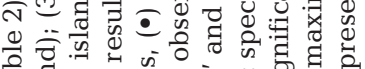

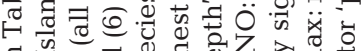

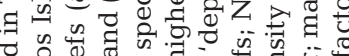

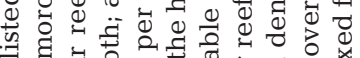

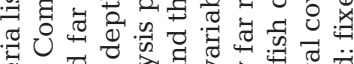

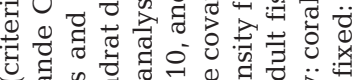

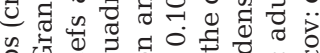

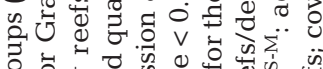

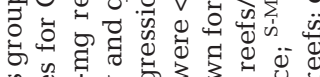
⿹勹巳

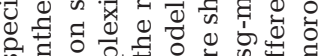
की हैं कि

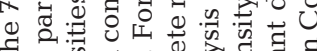

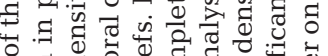

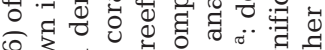

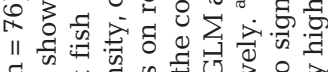

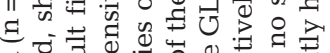

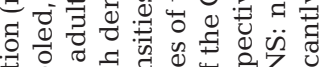

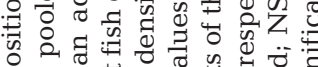

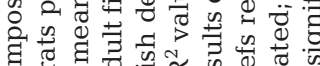

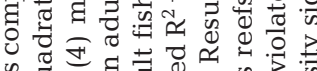

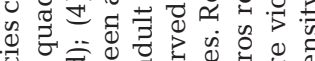

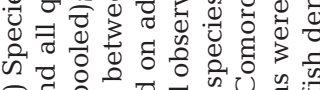

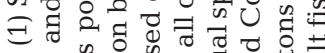

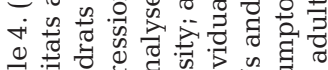

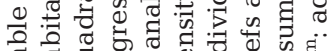

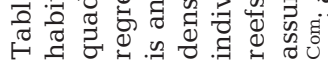

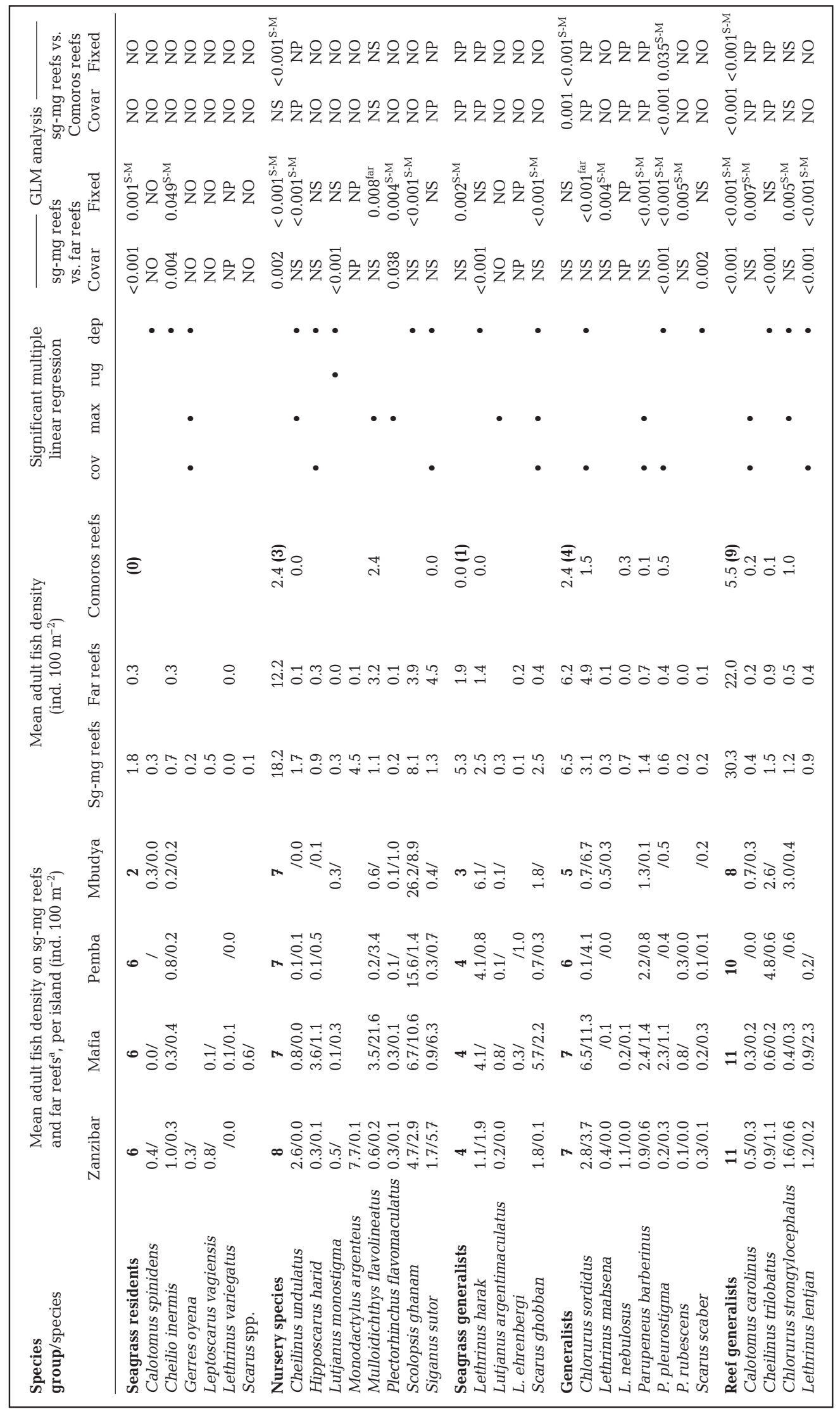




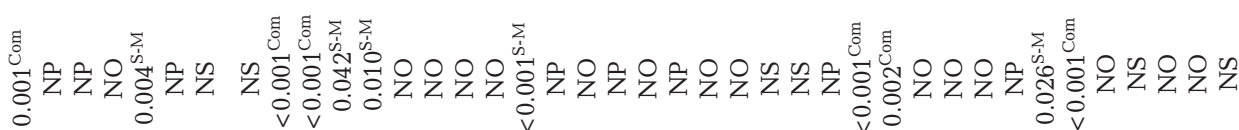

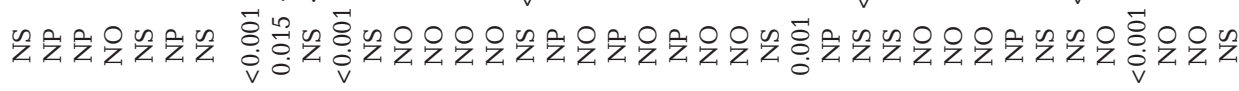

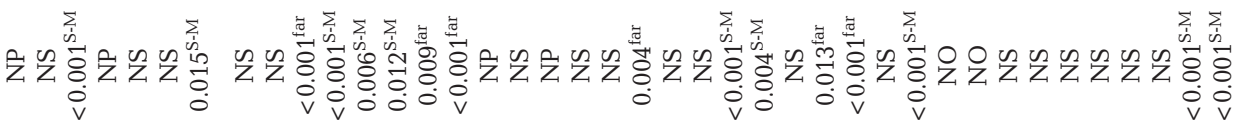

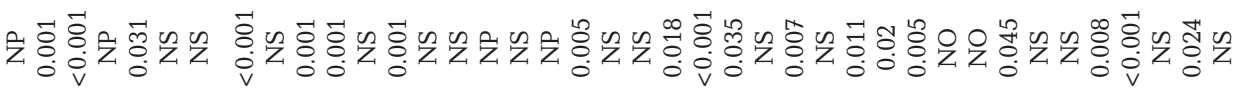

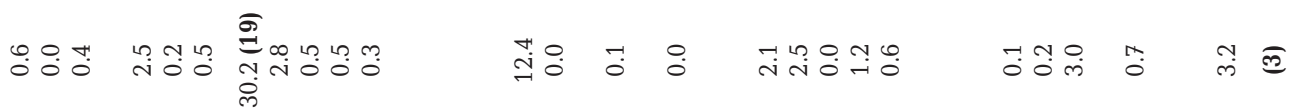

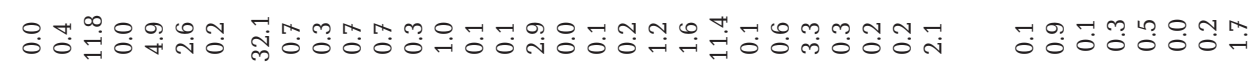

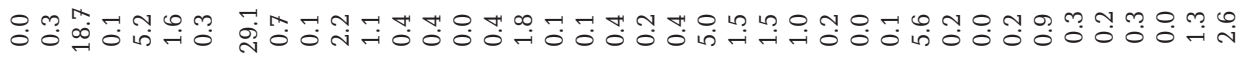

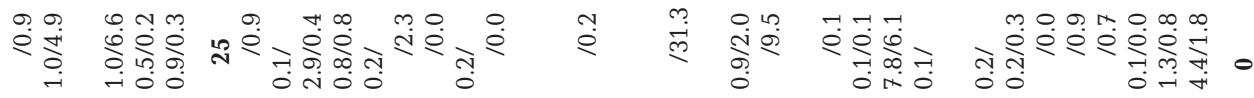

方势

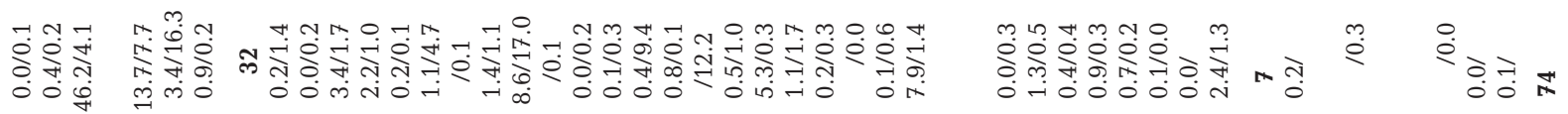

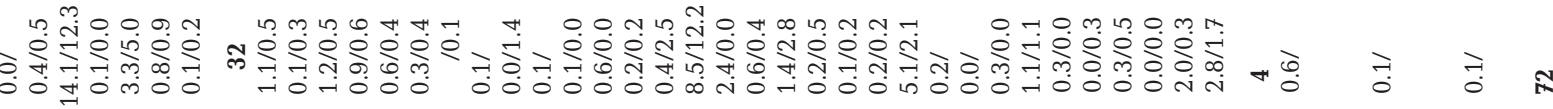

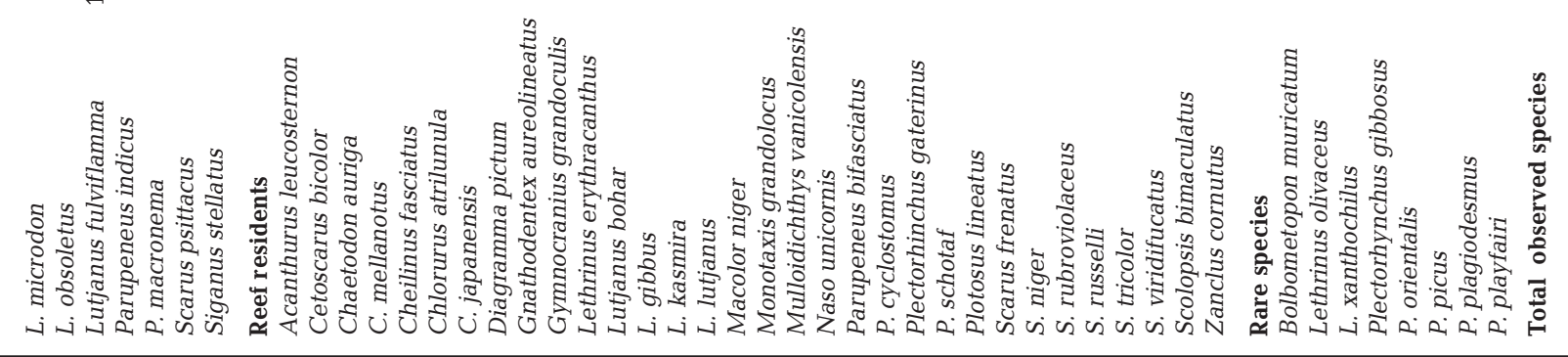



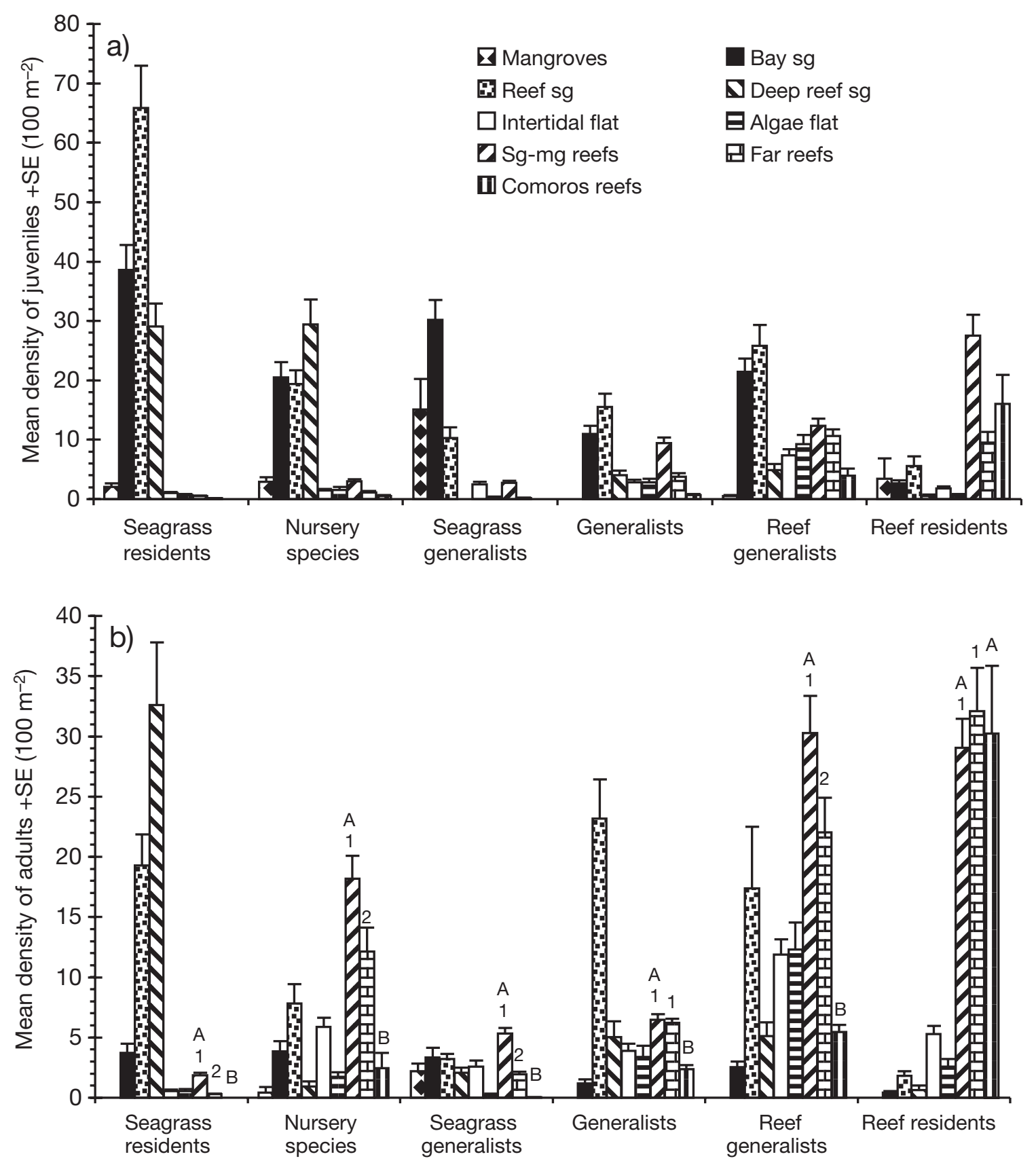

Fig. 3. Mean total densities of (a) juveniles and (b) adults per species group per habitat type. Significantly different adult densities $(p<0.05$, tested with GLM) between sg-mg reefs and Comoros reefs are indicated by different letters, while significant different densities between sg-mg reefs and far reefs are indicated by different numbers. See Table 1 for habitat abbreviations

The GLM comparison between sg-mg reefs and Comoros reefs of the effect of the presence of sg-mg areas on the adult fish densities per species group shows that densities of nursery species, generalists and reef generalists were significantly lower on Comoros reefs (Fig. 3b, Table 4). Sg residents were not observed on Comoros reefs at all, and densities of sg generalists were almost zero (not enough observations to perform a GLM). Also, total fish density was significantly lower on Comoros reefs (Fig. 2). The GLM comparison of adult densities of species groups between sg-mg reefs and far reefs shows that densities for all species groups were significantly higher on sg-mg reefs than on far reefs, except for generalists and reef residents (Fig. 3b, Table 4). Also, total fish density was significantly lower on far reefs (Fig. 2). 
The GLM comparison of adult densities between sgmg reefs and Comoros reefs at the level of individual species shows that 32 of the 36 species whose juveniles were observed in sg-mg habitats (sg residents, nursery species, seagrass generalists, generalists and reef generalists) were either absent from the Comoros reefs or were observed in very low densities (not enough observations to perform a GLM) or significantly lower densities than on sg-mg reefs (Table 4). Only 1 species from the nursery species group (Mulloidichthys flavolineatus) occurred on the Comoros reefs in comparable densities as on sg-mg reefs. Compared with densities on sg-mg reefs, only 2 species of reef generalists (Chlorurus strongylocephalus and Siganus stellatus) occurred in comparable densities, and 1 species (Lethrinus microdon) in higher densities on the Comoros reefs. All other species of generalists and reef generalists were not observed or occurred in low densities on the Comoros reefs (Fig. 4). Although many species of reef residents were not observed or only occurred in low densities on the Comoros reefs, this species group included the highest number of species for which no density differences were observed between sg-mg reefs and the Comoros reefs, or for which densities on the Comoros reefs were significantly higher.

The GLM comparison of adult densities of all individual species between sgmg reefs and far reefs shows that all species of sg residents were not observed, occurred in low densities (not enough observations to perform a GLM) or in significantly lower densities on the far reefs (Fig. 4, Table 4). The other species groups whose juveniles were observed in sg-mg areas (nursery species, seagrass generalists, generalists and reef residents) consisted of some species that showed significantly higher densities on far reefs than on sg-mg reefs and/or species that showed comparable densities between reefs. However, of the 36 species whose juveniles were observed in sg-mg habitats (sg residents, nursery species, seagrass generalists, generalists and reef generalists), the majority of these species (25 species, 69\%) were either absent from far reefs, were observed in low densities (not enough observations to perform a GLM) or significantly lower densities than on sg-mg reefs. Although the reef residents also included species with significantly higher densities on sg-mg reefs, most species did not show differences between reefs or had significantly higher densities on far reefs. Although mean adult fish densities on sg-mg reefs or far reefs on Zanzibar, Mafia, Pemba and Mbudya were not similar between the islands, the patterns of occurrence of species on either sg-mg reefs and far reefs as described above were found on all islands (Table 4).

\section{DISCUSSION}

\section{Species groups and habitat utilisation}

Of all investigated habitat types other than the reef, shallow seagrass beds harboured the highest fish densities. Although mangroves, macroalgae, deep seagrass beds and the intertidal flat were used by several species of fish, densities were low in comparison with those in shallow seagrass beds. Although the composition of the species groups varied per island, differences in species composition between the islands Zanzibar, Mafia and Pemba where mangrove, seagrass as well

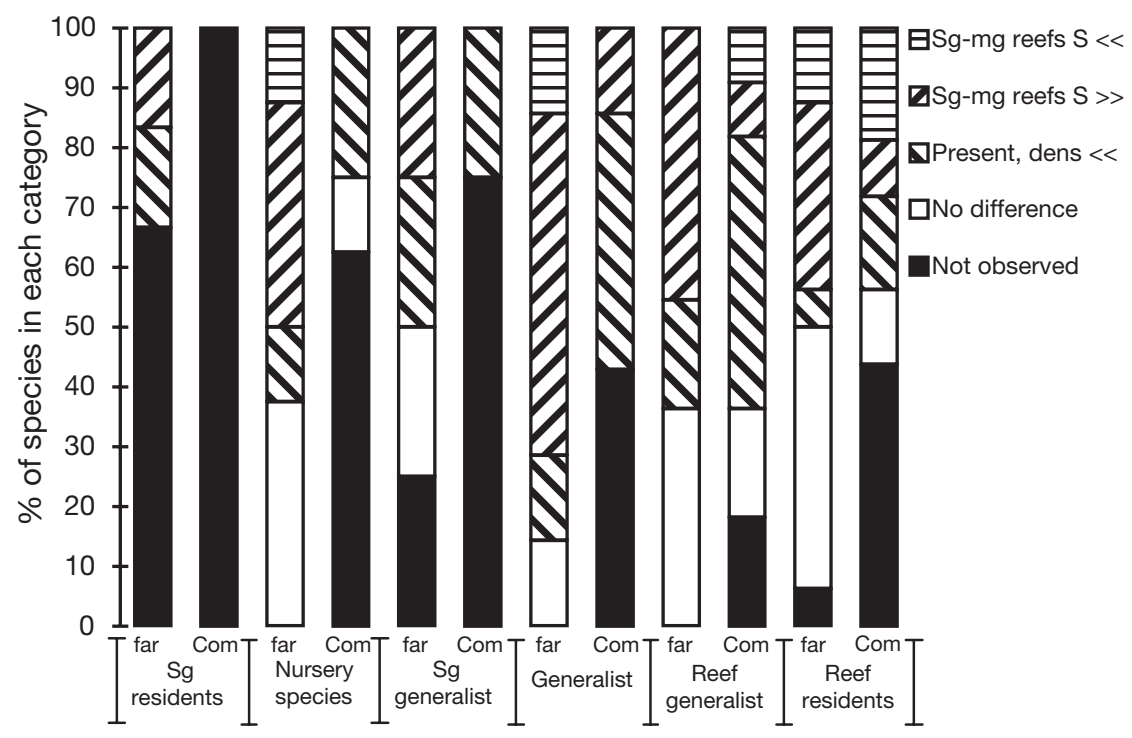

Fig. 4. Overview of GLM results of individual species, per species group (see also Table 4). Mean adult species densities were compared (1) between sg-mg reefs and far reefs (far) and (2) between sg-mg reefs and Comoros reefs (Com). GLM results were classified as follows: (1) mean adult species density on sg-mg reefs was significantly lower than on far reefs or Comoros reefs (Sg-mg reefs $\mathrm{S}<<$; $(2)$ mean adult species density on sg-mg reefs was significantly higher than on far reefs or Comoros reefs (Sg-mg reefs $\mathrm{S}>>$ ); (3) species occurred on reefs (sg-mg reefs, far reefs or Comoros reefs) but adult densities were too low to be tested using GLM (Present, dens $<<$ ); (4) no significant difference was observed between species densities on sg-mg reefs and far reefs or Comoros reefs (No difference); (5) no individuals of a species were observed on far reefs or on Comoros reefs (Not observed). For each species group, the bar shows the percentage of species in that particular group that showed a possible GLM result relative to the total number of species in the group. Sg: seagrass; see Table 1 for habitat abbreviations 
as reef habitats were sampled, were relatively small. Because the observed species community is relatively similar between these islands, the observed utilisation of available habitats by juvenile fish is regarded as a general pattern, rather than as a specific island effect. For 36 of the 76 selected fish species, juveniles clearly made use of areas where seagrass beds and mangroves were present, and for 18 of these species (all sg residents, nursery species and sg generalists) $>70 \%$ of their juvenile density was found in these areas. Since juvenile fish densities of all species groups whose juveniles were found in these areas were highest in the seagrass habitats, it is likely that seagrass habitats function as the most important juvenile habitats in areas outside the reef. In contrast to the high densities in seagrass habitats, the low fish densities and species richness in mangroves quantitatively support the suggestion that mangroves in the Indo-Pacific region are hardly used as a habitat by reef fish (Quinn \& Kojis 1987, Robertson \& Duke 1987, Thollot \& Kulbicki 1988, Kimani et al. 1996, Laroche et al. 1997, Huxham et al. 2004).

A study in the Caribbean that used an approach comparable to that of the present study indicated that 30 of the 85 selected coral reef species used seagrass beds and mangroves as an important juvenile habitat (Nagelkerken et al. 2000a). In comparison with the number of species that used seagrass and mangrove nurseries in the latter study, the present study showed 36 of the 76 selected reef species used seagrass beds as an important juvenile habitat. The present study thus indicates that seagrass beds in the Indo-Pacific can, in some cases, function as equally important juvenile habitats for coral reef fish as seagrass beds and mangroves in the Caribbean.

In addition to seagrass habitats, juveniles of species of generalists and reef generalists are clearly able to use other available habitats, in particular reef habitats. These species might therefore be regarded as nursery opportunists, rather than as species that are highly dependent on 1 habitat type for their juveniles (Lenanton \& Potter 1987). Therefore, as regards the entire community of the selected reef fish species, the present study shows that shallow seagrass beds and reef habitats are the most important juvenile habitats for reef fish in a landscape presenting a mosaic of coastal habitats.

Of all species groups, adult fish densities on reefs close to areas with seagrass beds were highest for nursery species and reef generalists. For nursery species, juveniles were predominantly found in seagrass habitats. Although juveniles of the reef generalists were observed in a variety of habitats, relatively high juvenile densities were observed in seagrass beds too. Although there is no direct evidence supporting con- nectivity between these seagrass and reef habitats, ontogenetic migrations from the seagrass habitat to the reef habitat are likely, since adults of these 2 species groups showed much higher densities on reefs close to areas with seagrass beds.

\section{Effect of the presence of areas with seagrass beds on adult fish densities}

The absence of extensive areas of seagrass nurseries at Grande Comoros most likely explains the absence or low adult densities of all species groups there, except reef residents. Individual species within the various species groups mostly show the same pattern. This may also be the most likely explanation for the observations on far reefs. Here, all species groups whose juveniles were observed in seagrass areas showed reduced adult densities, except generalists. The majority of the species in all groups, except reef residents, were absent from the far reefs or had higher densities on reefs adjacent to seagrass areas than on far reefs. These observations support the hypothesis that the presence of areas with important juvenile habitats, such as seagrass beds, has a positive effect on the densities of adults on adjacent coral reefs of species that use these habitats as juveniles. This has also been suggested for coral reef species that use seagrass-mangrove nurseries on Caribbean islands (Ley et al. 1999, Nagelkerken et al. 2000a, 2002, Ley \& McIvor 2002, Dorenbosch et al. 2004, Halpern 2004, Mumby et al. 2004). Hence, the utilisation of seagrass habitats as a juvenile habitat by coral reef fishes in some regions of the Indo-Pacific can be as important as in the Caribbean.

Although the effect of the absence or presence of seagrass areas on adult fish densities is clearly visible in comparisons with both the Comoros reefs and the far reefs, various individual species with juveniles found in the seagrass areas did not show this pattern. These species occurred in comparable or even higher adult densities on the Comoros reefs (Chlorurus strongylocephalus, Lethrinus microdon, Mulloidichthys flavolineatus and Siganus stellatus) or the far reefs (Cheilinus trilobatus, Chlorurus sordidus, Hipposcarus harid, Lethrinus harak, L. obsoletus, Lutjanus monostigma, Mulloidichthys flavolineatus, Parupeneus macronema, Scarus scaber, S. psittacus and Siganus sutor). The most likely explanation for this distribution pattern is recruitment and survival of juveniles on reefs (Nagelkerken et al. 2000a,b, 2002, Dorenbosch et al. 2004). Another possible explanation for the presence of their adults on far reefs would be the migration of adults or subadults of these species from sg-mg areas via sg-mg reefs to far reefs. Tulevech \& Recksiek (1994) and 
Chapman \& Kramer (2000) only showed very limited movements of coral reef fishes between reefs that were separated from each other (several metres to $1 \mathrm{~km}$ ). Since the distance between the far reefs and sg-mg reefs in the present study is large (on average $17.2 \mathrm{~km}$ ) and the far reefs are disconnected from the sg-mg areas by deep waters, migration is most likely to be low.

In conclusion, the results of the present study show that in an area featuring various coastal habitats in the western Indian Ocean, both shallow seagrass and coral reef habitats are favoured by juvenile fish over other available shallow-water habitats. For nursery species and reef generalists (see species list, Table 4) juvenile densities are very high in seagrass beds and considerably lower on coral reefs, while adult densities show the opposite pattern. For these species, seagrass beds function as an important juvenile habitat, and ontogenetic migrations to adjacent coral reefs are likely. In total, of the 36 species that used seagrass beds as a juvenile habitat, 25 showed higher adult densities on coral reefs adjacent to these areas than on far reefs. For these species, it is likely that the presence of seagrass beds contributes to the fish populations on adjacent coral reefs, suggesting an ecological connectivity between these habitats. However, eleven of these 36 species that used seagrass beds as a juvenile habitat were also able to sustain adult populations in equal densities on reefs situated far from these habitats, suggesting that these species do not entirely depend on the presence of seagrass beds as nurseries. As a contribution to the debate regarding the importance of IndoPacific mangroves and seagrass beds as a habitat for juvenile coral reef fish, it can be stated that in the present study seagrass beds had high value as a juvenile habitat, whereas the value of mangroves was low.

Acknowledgements. This study was funded by Nuffic through the ENVIRONS-MHO programme, by Quo Vadis fund of the Radboud University Nijmegen, by PADI's Aware project and by Sensation Divers, Nungwi (Zanzibar). Sensation Divers provided facilities and technical advice on the island of Zanzibar, while logistic support was provided by Swahili Divers on the island of Pemba, and by the Mafia Marine Park on the island of Mafia. Kisandra Divers provided logistic support on Grande Comoros. We thank the management and staff of the Institute of Marine Science in Zanzibar for the use of their facilities and for their support. Earlier versions of the manuscript benefited from comments of 3 anonymous reviewers. This is publication No. 359 of the Centre for Wetland Ecology.

\section{LITERATURE CITED}

Ault TR, Johnson CR (1998) Spatial variation in fish species richness on coral reefs: habitat fragmentation and stochastic structuring processes. Oikos 82:354-364
Beck MW, Heck KL, Able KW, Childers DL and 9 others (2001) The identification, conservation, and management of estuarine and marine nurseries for fish and invertebrates. Bioscience 51:633-641

Birkeland C, Amesbury SS (1988) Fish-transect surveys to determine the influence of neighbouring habitat on fish community structure in the tropical Pacific. Proc 8th Int Coral Reef Symp 97:195-202

Blaber SJM, Blaber TG (1980) Factors affecting the distribution of juvenile estuarine and inshore fish. J Fish Biol 17: 143-162

Chapman MR, Kramer DL (2000) Movements of fishes within and among fringing coral reefs in Barbados. Environ Biol Fish 57:11-24

de Boer WF, van Schie AMP, Jocene DF, Mabote ABP, Guissamulo A (2001) The impact of artisanal fishery on a tropical intertidal benthic fish community. Environ Biol Fish 61:213-229

Dorenbosch M, van Riel MC, Nagelkerken I, van der Velde G (2004) The relationship of reef fish densities to the proximity of mangrove and seagrass nurseries. Estuar Coast Shelf Sci 60:37-48

Froese R, Pauly D (eds) (2003) FishBase. World Wide Web electronic publication (www.fishbase.org) 24-6-2003

Garpe KC, Öhman MC (2003) Coral and fish distribution patterns in Mafia Island Marine Park, Tanzania: fish-habitat interactions. Hydrobiologia 498:191-211

Green AL (1996) Spatial, temporal and ontogenetic patterns of habitat use by coral reef fishes (Family Labridae). Mar Ecol Prog Ser 133:1-11

Gullström M, de la Torre Castro M, Bandeira SO, Björk M, Dahkberg M, Kautsky N, Rönnbäck P, Öhman MC (2002) Seagrass ecosystems in the Western Indian Ocean. Ambio 31:588-596

Halpern BS (2004) Are mangroves a limiting resource for two coral reef fishes? Mar Ecol Prog Ser 272:93-98

Huxham M, Kimani EN, Augley J (2004) Mangrove fish: a comparison of community structure between forested and cleared habitats. Estuar Coast Shelf Sci 60:637-647

Jenkins GP, Wheatley MJ (1998) The influence of habitat structure on nearshore fish assemblages in a southern Australian embayment: Comparison of shallow seagrass, reef-algal and unvegetated sand habitats, with emphasis on their importance to recruitment. J Exp Mar Biol Ecol 221:147-172

Jiddawi NS, Stanley RD (1997) Fisheries stock assessment in the traditional fishery sector: the information needs. Canadian International Development Agency, Zanzibar Town/Dar es Salam

Jones RS, Chade JA (1975) Community structure and distribution of fishes in an enclosed high island lagoon in Guam. Micronesia 11:127-148

Kimani EN, Mwatha GK, Wakwabi EO, Ntiba JM, Okoth BK (1996) Fishes of a shallow tropical mangrove estuary, Gazi, Kenya. Mar Freshw Res 47:857-868

Kochzius M (1997) Interrelation of ichthyofauna from a seagrass meadow and coral reef in the Philippines. Proc 5th Indo-Pacific Fisheries Conf, Nouméa, 1997:517-535

Lal P, Swamy K, Singh P (1984) Mangrove ecosystem fisheries associated with mangroves and their management. Mangrove fishes in Wairiki Creek and their implications on the management of resources in Fiji. UNESCO Rep Mar Sci 27:93-108

Laroche J, Baran E, Rasoanandrasana NB (1997) Temporal patterns in a fish assemblage of a semiarid mangrove zone in Madagascar. J Fish Biol 51:3-20

Lenanton RCJ, Potter IC (1987) Contribution of estuaries to 
commercial fisheries in temperate western Australia and the concept of estuarine dependence. Estuaries 10:28-35

Ley JA, McIvor CC (2002) Linkages between estuarine and reef fish assemblages: enhancement by the presence of well-developed mangrove shorelines. In: Porter J, Porter M (eds) The Everglades, Florida Bay and Coral Reefs of the Florida Keys: an ecosystem sourcebook. CRC Press, Boca Raton, FL, p 539-562

Ley JA, McIvor CC, Montague CL (1999) Fishes in mangrove prop root habitats of northeastern Florida Bay: distinct assemblages across an estuarine gradient. Estuar Coast Shelf Sci 48:710-723

Little MC, Reay PJ, Grove SJ (1988) The fish community of an East African mangrove creek. J Fish Biol 32:729-747

Luckhurst BE, Luckhurst K (1978) Analysis of the influence of substrate variables on coral reef fish communities. Mar Biol 49:317-323

Mumby PJ, Edwards AJ, Arias-Gonzalez JE, Lindeman PG and 7 others (2004) Mangroves enhance the biomass of coral reef fish communities in the Caribbean. Nature 427: $533-536$

Nagelkerken I, van der Velde G (2002) Do non-estuarine mangroves harbour higher densities of juvenile fish than adjacent shallow-water and coral reef habitats in Curaçao (Netherlands Antilles)? Mar Ecol Prog Ser 245:191-204

Nagelkerken I, Dorenbosch M, Verberk WCEP, Cocheret de la Morinière E, van der Velde G (2000a) Importance of shallow-water biotopes of a Caribbean bay for juvenile coral reef fishes: patterns in biotope association, community structure and spatial distribution. Mar Ecol Prog Ser 202:175-192

Nagelkerken I, van der Velde G, Gorissen MW, Meijer GJ, van't Hof T, den Hartog C (2000b) Importance of mangroves, seagrass beds and the shallow coral reef as a nursery for important coral reef fishes, using a visual census technique. Estuar Coast Shelf Sci 51:31-44

Nagelkerken I, Roberts CM, van der Velde G, Dorenbosch M, van Riel $\mathrm{MC}$, Cocheret de la Morinière $\mathrm{E}$, Nienhuis $\mathrm{PH}$ (2002) How important are mangroves and seagrass beds for coral-reef fish? The nursery hypothesis tested on an island scale. Mar Ecol Prog Ser 244:299-305

Nakamura Y, Sano M (2004a) Comparison between community structures of fishes in Enhalus acoroides and Thalassia hemprichii dominated seagrass beds on fringing coral reefs in the Ryuku Islands, Japan. Ichthyol Res 51:38-45

Nakamura Y, Sano M (2004b) Overlaps in habitat use of fishes between a seagrass bed and adjacent coral and sand areas at Amitori Bay, Iriomote Island, Japan: Importance of the seagrass bed as juvenile habitat. Fish Sci 70:788-803

Öhman MC, Rajasuriya A (1998) Relationships between habi-

Editorial responsibility: Otto Kinne (Editor-in-Chief), Oldendorf/Luhe, Germany tat structure and fish communities on coral and sandstone reefs. Environ Biol Fish 53:19-31

Parrish JD (1989) Fish communities of interacting shallowwater habitats in tropical oceanic regions. Mar Ecol Prog Ser 58:143-160

Pollard DA (1984) A review of ecological studies on seagrassfish communities, with particularly reference to recent studies in Australia. Aquat Bot 18:3-42

Polunin NVC, Roberts CM (1993) Greater biomass and value of target coral-reef fishes in two small Caribbean marine reserves. Mar Ecol Prog Ser 100:167-176

Quinn TP, Kojis BL (1987) The influence of diel cycle, tidal direction and trawl alignment on beam trawl catches in an equatorial estuary. Environ Biol Fish 19:297-308

Richmond MD (2002) A field guide to the seashores of Eastern Africa and the Western Indian Ocean islands. Sida/SAREC-UDSM, Dar es Salaam

Robertson AI, Duke NC (1987) Mangroves as nursery sites: comparisons of the abundance and species composition of fish and crustaceans in mangroves and other nearshore habitats in tropical Australia. Mar Biol 96:193-205

Robertson AI, Duke NC (1990) Mangrove fish-communities in tropical Queensland, Australia: spatial and temporal patterns in densities, biomass and community structure. Mar Biol 104:369-379

Rossier O, Kulbicki M (2000) A comparison of fish assemblages from two types of algal beds and coral reefs in the south-west lagoon of New Caledonia. Cybium 24:3-26

Sheridan P, Hays C (2003) Are mangroves nursery habitat for transient fishes and decapods? Wetlands 23:449-458

Sheskin DJ (1997) Handbook of parametric and nonparametric statistical procedures. CRC Press, New York

Sokal RR, Rohlf FJ (1995) Biometry, 3rd edn. WH Freeman, New York

Thollot P, Kulbicki M (1988) Overlap between the fish fauna inventories of coral reefs, soft bottoms and mangroves in Saint-Vincent Bay (New Caledonia). Proc 6th Int Coral Reef Symp Australia 2:613-618

Tulevech SM, Recksiek CW (1994) Acoustic tracking of adult white grunt, Haemulon plumieri, in Puerto Rico and Florida. Fish Res 19:301-319

Wakwabi EO, Mees J (1999) The epibenthos of the backwaters of a tropical mangrove creek (Tudor creek, Mombasa, Kenya). Neth J Zool 49:189-206

Watson RA, Quinn TJ (1997) Performance of transect and point count underwater visual census methods. Ecol Model 104:103-112

Williams DM (1991) Patterns and processes in the distribution of coral reef fishes. In: Sale P (ed) The ecology of fishes on coral reefs. Academic Press, New York, p 437-474

Submitted: October 20, 2004; Accepted: May 3, 2005

Proofs received from author(s): October 11, 2005 